\title{
FUTURE OF OIL AND GAS TRADE OF KAZAKHSTAN IN THE EUROPEAN UNION CONTEXT - APPLICATION OF TIME SERIES ANALYSIS
}

\section{Alisher Kabylda*, Natália Turčeková, Dominika Čeryová, Stefaniia Belinska, Filip Valentíni}

\author{
Slovak University of Agriculture in Nitra, Slovakia
}

Energy is a fundamental factor in cooperation between Kazakhstan and the European Union; both sides strive for energy security but understand it differently. For Kazakhstan, the European Union is the primary export market for energy resources, a source of investment and technology. For the European Union, Kazakhstani oil and gas are the most valuable energy resources of the Central Asian region. The relevance of the chosen topic is that oil and gas are of crucial importance for the economy of Kazakhstan. In the future, Kazakhstan is going to increase production with the European Union. Kazakhstan's oil and gas industry can be attributed to one of the leading sectors of the country's economy. The purpose of the scientific paper is to analyse the oil and gas trade between Kazakhstan and the European Union using a time series model to examine Kazakhstan's oil and gas trade flow, in order to describe its top 5 trade partners in the European Union, also providing objective information on the results and prospects of development of cooperation between Kazakhstan and the European Union in the field of oil and gas trade.

Keywords: oil; gas; trade; export; import; production; barrel

Since the beginning of this century, the economy of Kazakhstan has demonstrated stable high growth rates: the gross domestic product (GDP) of the country increases annually by more than $9 \%$. This circumstance arouses particular interest in the study of the role of the oil and gas sector in the development of the Republic's economy - the main stimulator of its current economic boom (Babak, 2006).

The fuel and energy sectors are a vital area and a fundamental factor in cooperation between Kazakhstan and the European Union. This is reflected in the strategic documents and the state program of Kazakhstan "Way to Europe" (Laumulin, 2020). The Republic belongs to a group of States that have strategic reserves of hydrocarbons and are gradually increasing their influence on the formation of the energy market of the world oil market. In 2015, the parties signed a new long-term Partnership Agreement, the central place in which is given to energy issues.

At the same time, Kazakhstan faces specific difficulties and risks in connection with accelerated plans to develop its energy sector. Among them are ensuring the sustainability of the industry, a price shock, and a decrease in the growth rate of production, which leads to a reduction in income and a reduction of economic growth. The most essential task remains the rational use and distribution of oil and gas revenues (Ketova, 2017).

In order to analyse Kazakhstan's oil and gas trade with the European Union, we decided to conduct statistical macro and micro analyses, such as time series, namely multiplicative model in order to predict future trends and trading potentials of the two markets and identify Kazakhstan's top 5 partners in the European Union trade in oil, gas and oil products and give a quarterly forecast of dynamics of oil and gas export from Kazakhstan to the European Union members.

\section{Material and methods}

In this research paper, we used a time series analysis method, namely a multiplicative model for reviewing and analysing the dynamics of exports in the field of oil and gas from the Republic of Kazakhstan to the members of the
European Union. During the study of this topic, we used historical data for the last 20 years, namely quarterly financial data from 1999 to 2019. As a result of the initial analysis, the ranking of the top 5 partners in the European Union was determined. The objectives of studying multiplicative model are seeking to predict the future based on knowledge of the past, manage the process generating the series, try to find out the mechanism underlying the process, and clear the time series of components that obscure its dynamics (Egger, 2003). At the final part we predicted the dynamics of growth and decline in the export of these products between the two trading partners. In the conclusion of this work, we identified the critical internal and external factors that affect the dynamics of growth and decline of this trade model (Baier, 2009).

\section{Multiplicative model}

The primary assumption underlying the analysis of time series is as follows: factors affecting the object under study in the present and in the past will change it in the future. Thus, the main goals of time series analysis are to identify and identify factors that are relevant to forecasting (Anderson, 1979). To achieve this goal, many mathematical models have been developed that are designed to study the oscillations of the components included in the time series model. Probably the most common one is the classic multiplicative model for annual, quarterly, and monthly data. As we mentioned above, we used quarterly data from 1999 to 2019.

First of all, we examined the dynamics of growth and recession with the European Union member states as a whole, then based on the total volume of trade in the industry data, and afterwards, we identified the top 5 partners. They are Germany, Italy, France, the Netherlands, and Poland.

For the purpose of analysis and forecasting, we used a multiplicative model of time series analysis:

$$
Y_{t}=S_{t} \times I_{t} \times T_{t}
$$

where: 
$Y_{t} \quad$ - time series value

$Y_{t} \quad$ - seasonal component

$Y_{t} \quad$ - irregular component

$Y_{t} \quad-$ trend component

All components comprise historical time series data. The goal is that we want to be able to understand how to export value moves through time and then be able to project that into perhaps next coming years. By the end of this analysis, we should be able to give prediction or forecasts.

\section{Results and discussion}

\section{Kazakhstan - the European Union (table 1, figure 1)}

As a part of the analysis, it is known that the dynamics of growth in oil and gas exports from the Republic of Kazakhstan to the EU countries had a fluctuating trend. The maximum export volume was recorded in the $3^{\text {rd }}$ quarter of 2013, where it was equal to $€ 808082689$. The minimum export volume was in the $1^{\text {st }}$ quarter of 1999 , where it was equivalent to $€ 56069136$. As you can see, the long-term trend of product exports is obscured by many fluctuations. Thus, visual analysis of the graph does not allow us to say that the data is trending. Considering this issue, we applied the moving average and centred moving average methods. After using these methods, we calculated that the maximum and minimum centred moving values are equal to $€ 663353078$ in $3^{\text {rd }}$ quarter, 2013 and $€ 77728036$ in $3^{\text {rd }}$ quarter, 1999, respectively.

As a result of the analysis of the multiplicative model of time series there was predicted the dynamics of export of oil and gas of Kazakhstan to the EU for 2020. Thus, $1^{\text {st }}$ quarter is equal to $€ 428433854 ; 2^{\text {nd }}$ quarter is equal to $€ 654663179 ; 3^{\text {rd }}$ quarter is equal to $€ 685481701$; and $4^{\text {th }}$ quarter is equal to $€ 716744895$. The dynamics of the time series will be positive from $1^{\text {st }}$ quarter till $4^{\text {th }}$ quarter of 2020 .

\section{Kazakhstan - Germany (table 2, figure 2)}

As a part of the analysis, it is known that the dynamics of growth in oil and gas exports from the Republic of Kazakhstan to Germany had a fluctuating trend. The maximum export volume was in the $3^{\text {rd }}$ quarter of 2013, where it was equal to $€ 368667412$. The minimum export volume was in the $1^{\text {st }}$ quarter of 1999, where it was equivalent to $€ 16490127$. As you can see, the long-term trend of product exports is obscured by many fluctuations. Thus, visual analysis of the graph does not allow us to say that the data is trending. Considering this issue, we applied the moving average and centred moving average methods. After using these methods, we calculated that the maximum and minimum centred moving values were equal to $€ 215081565$ in $2^{\text {nd }}$ quarter of 2013 and $€ 19859975$ in $3^{\text {rd }}$ quarter of 1999, respectively.

As a result of the analysis of the multiplicative model of time series there was predicted dynamics of export of oil and gas of Kazakhstan to

Table 1 Historical data of time series from 1999 till 2020 for export of oil and gas to the EU

\begin{tabular}{|c|c|c|c|c|c|c|c|}
\hline$t$ & Year & Quarter & Export value & Moving average (4) & Deseasonalize & Tt & Forecast \\
\hline 81 & \multirow{4}{*}{2019} & 1 & $€ 469509710$ & $€ 514449040$ & $€ 670728157$ & $€ 589814726$ & $€ 412870308$ \\
\hline 82 & & 2 & $€ 473243627$ & $€ 507930250$ & $€ 446456252$ & $€ 595373135$ & $€ 631095524$ \\
\hline 83 & & 3 & $€ 612292986$ & $€ 515461761$ & $€ 556629987$ & $€ 600931545$ & $€ 661024699$ \\
\hline 84 & & 4 & $€ 506800720$ & & $€ 444562035$ & $€ 606489954$ & $€ 691398548$ \\
\hline 85 & \multirow{4}{*}{2020} & 1 & & & & $€ 612048364$ & $€ 428433855$ \\
\hline 86 & & 2 & & & & $€ 617606773$ & $€ 654663180$ \\
\hline 87 & & 3 & & & & $€ 623165183$ & $€ 685481701$ \\
\hline 88 & & 4 & & & & $€ 628723592$ & $€ 716744895$ \\
\hline
\end{tabular}

Source: own elaboration based on ec.europa.eu (2020)

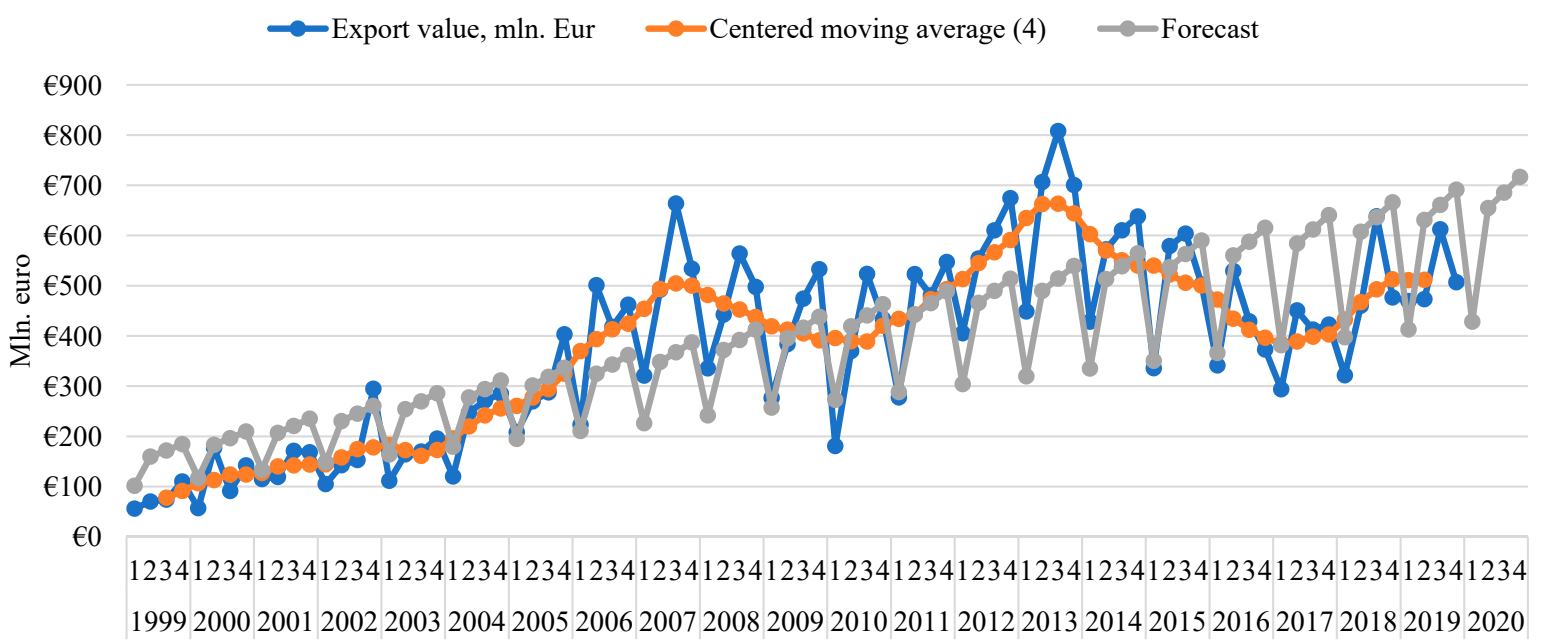

Figure 1 Time Series analysis and forecasts for oil and gas export to the European Union Source: own elaboration based on ec.europa.eu (2020) 
Table 2 Historical data of time series from 1999 till 2020 for export of oil and gas to Germany

\begin{tabular}{|c|c|c|c|c|c|c|c|}
\hline$t$ & Year & Quarter & Export value & Moving average (4) & Deseasonalize & Tt & Forecast \\
\hline 81 & \multirow{4}{*}{2019} & 1 & $€ 94435874$ & $€ 124224960$ & $€ 131046941$ & $€ 144782631$ & $€ 104334173$ \\
\hline 82 & & 2 & $€ 108519976$ & $€ 107252968$ & $€ 104046449$ & $€ 145900169$ & $€ 152173216$ \\
\hline 83 & & 3 & $€ 114240743$ & $€ 101472100$ & $€ 99348889$ & $€ 147017707$ & $€ 169054855$ \\
\hline 84 & & 4 & $€ 88691806$ & & $€ 82157063$ & $€ 148135245$ & $€ 159917868$ \\
\hline 85 & \multirow{4}{*}{2020} & 1 & & & & $€ 149252783$ & $€ 107555482$ \\
\hline 86 & & 2 & & & & $€ 150370321$ & $€ 156835565$ \\
\hline 87 & & 3 & & & & $€ 151487859$ & $€ 174195059$ \\
\hline 88 & & 4 & & & & $€ 152605397$ & $€ 164743575$ \\
\hline
\end{tabular}

Source: own elaboration based on ec.europa.eu (2020)

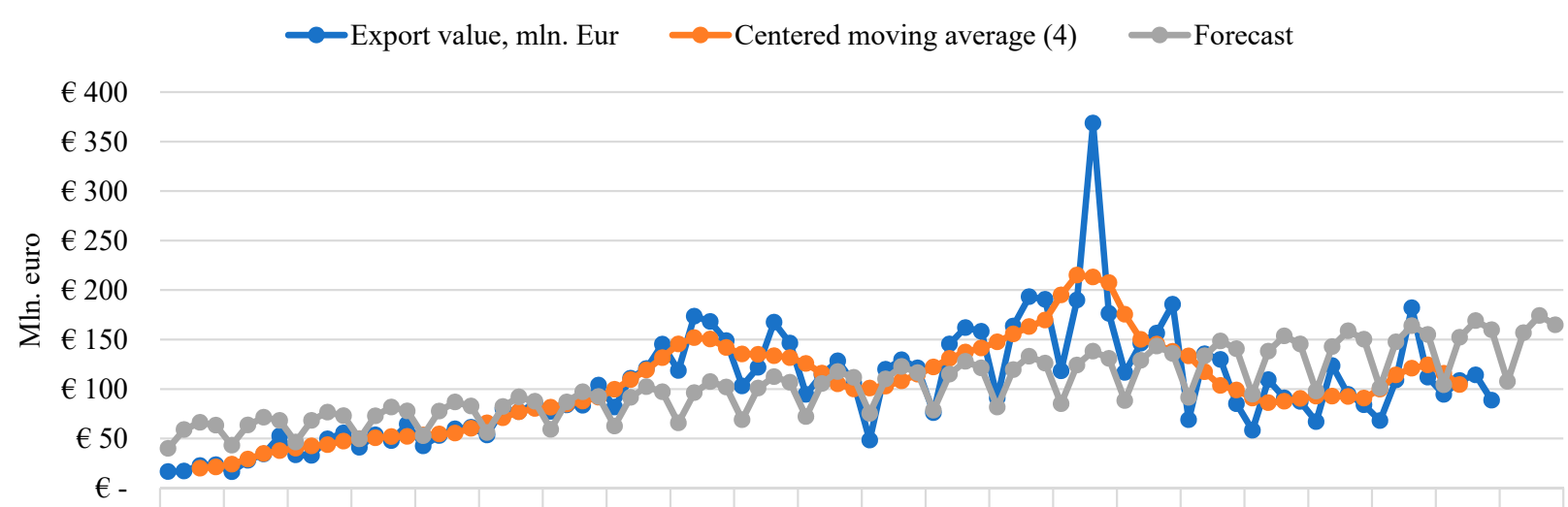

1234123412341234123412341234123412341234123412341234123412341234123412341234123412341234

1999200020012002200320042005200620072008200920102011201220132014201520162017201820192020

Figure 2 Time Series analysis and forecasts for oil and gas export to Germany Source: own elaboration based on ec.europa.eu (2020)

Germany for 2020. Thus, $1^{\text {st }}$ quarter is equal to $€ 107555482 ; 2^{\text {nd }}$ quarter is equal to $€ 156835564 ; 3^{\text {rd }}$ quarter is equal to $€ 174195058$; and $4^{\text {th }}$ quarter is equal to $€ 164743574$. The dynamics of time series for 2020 will be positive from $1^{\text {st }}$ till $3^{\text {rd }}$ quarter, and from $3^{\text {rd }}$ quarter to $4^{\text {th }}$ quarter, it will decrease.

\section{Kazakhstan - Italy (table 3, figure 3)}

As a part of the analysis, it is known that the dynamics of growth in oil and gas exports from the Republic of Kazakhstan to Italy had a fluctuating trend. The maximum export volume was marked in the $3^{\text {rd }}$ quarter of
2010, where it was equal to $€ 169916$ 522. The minimum export volume was in the $1^{\text {st }}$ quarter of 1999 , where it was equivalent to $€ 3858915$. As you can see, the long-term trend of product exports is obscured by many fluctuations. Thus, visual analysis of the graph does not allow us to say that the data is trending. Considering this issue, we applied the moving average and centred moving average methods. After using these methods, we calculated that the maximum and minimum centred moving values are equal to $€ 111692650$ in $4^{\text {th }}$ quarter in 2018 and $€ 11677127$ in $3^{\text {rd }}$ quarter in 2000 , respectively.

Table 3 Historical data of time series from 1999 till 2020 for export of oil and gas to Italy

\begin{tabular}{|c|c|c|c|c|c|c|c|}
\hline$t$ & Year & Quarter & Export value & Moving average (4) & Deseasonalize & Tt & Forecast \\
\hline 81 & \multirow{4}{*}{2019} & 1 & $€ 144912503$ & $€ 113446459$ & $€ 215155314$ & $€ 83916811$ & $€ 56520078$ \\
\hline 82 & & 2 & $€ 73161584$ & $€ 91401073$ & $€ 76567982$ & $€ 84794274$ & $€ 81021900$ \\
\hline 83 & & 3 & $€ 67048467$ & $€ 87452729$ & $€ 55364585$ & $€ 85671737$ & $€ 103751497$ \\
\hline 84 & & 4 & $€ 64688360$ & & $€ 56831538$ & $€ 86549199$ & $€ 98514416$ \\
\hline 86 & \multirow{3}{*}{2020} & 2 & & & & $€ 88304125$ & $€ 84375602$ \\
\hline 87 & & 3 & & & & $€ 89181587$ & $€ 108002050$ \\
\hline 88 & & 4 & & & & $€ 90059050$ & $€ 102509495$ \\
\hline
\end{tabular}

Source: own elaboration based on ec.europa.eu (2020) 


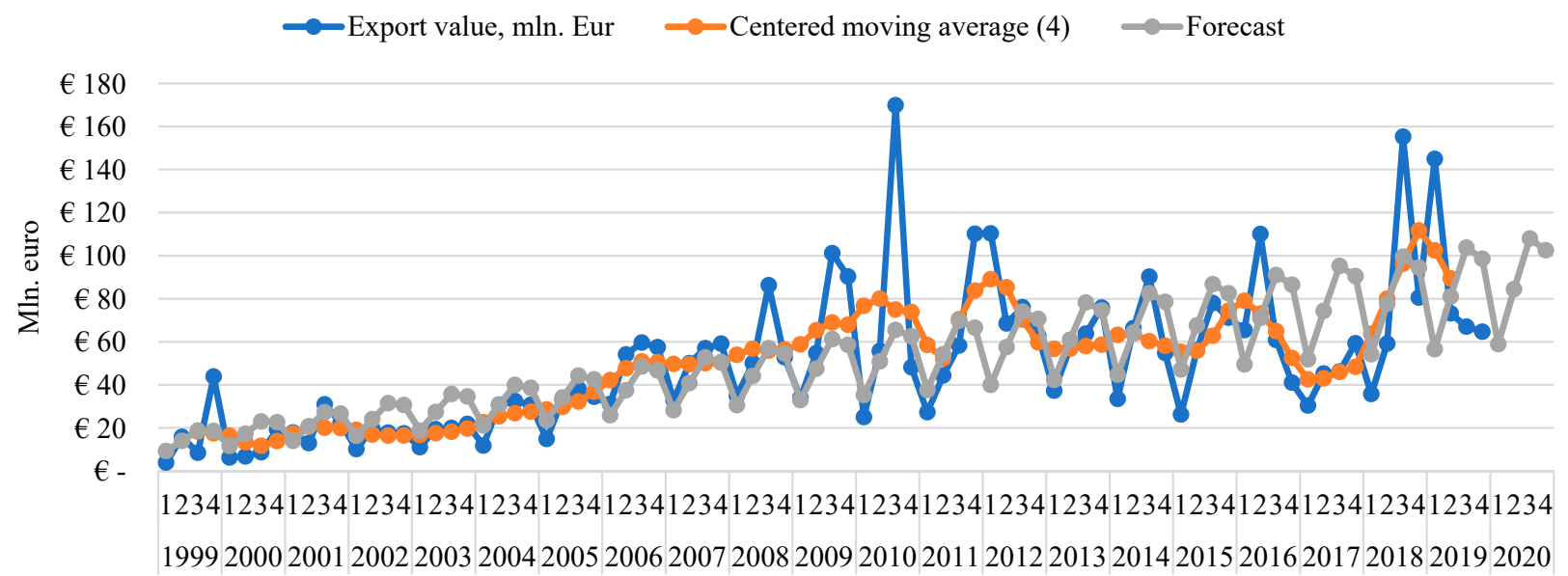

Figure 3 Time Series analysis and forecasts for oil and gas export to Italy Source: own elaboration based on ec.europa.eu (2020)

As a result of the analysis of the multiplicative model of time series there was predicted the dynamics of export of oil and gas of Kazakhstan to Italy for 2020. Thus, $1^{\text {st }}$ quarter is equal to $€ 58884050 ; 2^{\text {nd }}$ quarter is equal to $€ 84375602 ; 3^{\text {rd }}$ quarter is equal to $€ 108002050$ and $4^{\text {th }}$ quarter is equal to $€$ 102509 495. The dynamics of time series for 2020 will be positive from $1^{\text {st }}$ till $3^{\text {rd }}$ quarter, and from $3^{\text {rd }}$ quarter to $4^{\text {th }}$ quarter will decrease.

\section{Kazakhstan - France (table 4, figure 4)}

As a part of the analysis, it is known that the dynamics of growth in oil and gas exports from the Republic of Kazakhstan to France had a significant fluctuating trend. The maximum export volume was in the $2^{\text {nd }}$ quarter of 2006, where it was equal to $€ 166995$ 943. The minimum export volume was

Table 4 Historical data of time series from 1999 till 2020 for export of oil and gas to France

\begin{tabular}{|c|c|c|c|c|c|c|c|}
\hline$t$ & Year & Quarter & Export value & Moving average (4) & Deseasonalize & Tt & Forecast \\
\hline 81 & \multirow{4}{*}{2019} & 1 & $€ 19006298$ & $€ 25300352$ & $€ 29132163$ & $€ 51653430$ & $€ 33699540$ \\
\hline 82 & & 2 & $€ 28974487$ & $€ 41922110$ & $€ 25255751$ & $€ 52065542$ & $€ 59731836$ \\
\hline 83 & & 3 & $€ 97669017$ & $€ 45232422$ & $€ 111887169$ & $€ 52477653$ & $€ 45809013$ \\
\hline 84 & & 4 & $€ 35279887$ & & $€ 29777256$ & $€ 52889764$ & $€ 62663428$ \\
\hline 86 & \multirow{3}{*}{2020} & 2 & & & & $€ 53713987$ & $€ 61623004$ \\
\hline 87 & & 3 & & & & $€ 54126099$ & $€ 47247981$ \\
\hline 88 & & 4 & & & & $€ 54538210$ & $€ 64616495$ \\
\hline
\end{tabular}

Source: own elaboration based on ec.europa.eu (2020)

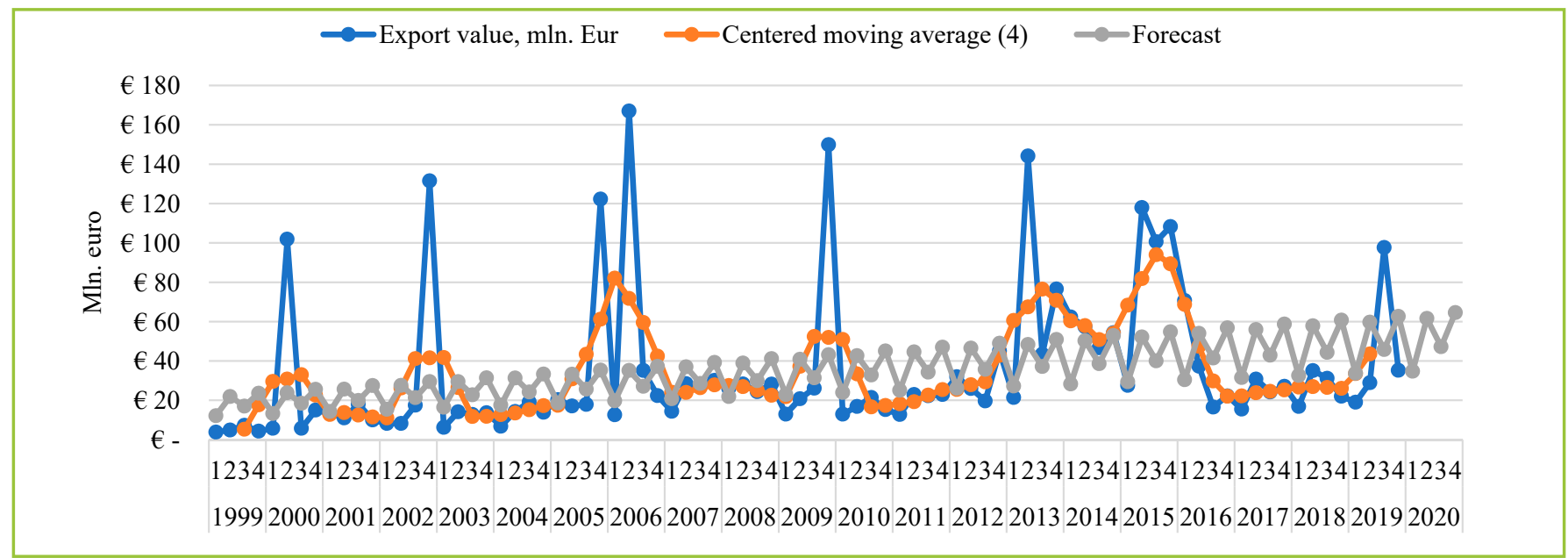

Figure 4 Time Series analysis and forecasts for oil and gas export to France Source: own elaboration based on ec.europa.eu (2020) 
in the $1^{\text {st }}$ quarter of 1999 , where it was equivalent to $€ 3876695$. As you can see, the long-term trend of product exports is obscured by many fluctuations. Thus, visual analysis of the graph does not allow us to say that the data is trending. Considering this issue, we applied the moving average and centred moving average methods. After using these methods, we calculated that the maximum and minimum centred moving values are equal to $€ 93997970$ in $3^{\text {rd }}$ quarter in 2015 and $€ 5315431$ in $3^{\text {rd }}$ quarter in 1999, respectively.

As a result of the analysis of the multiplicative model of time series there was predicted the dynamics of export of oil and gas of Kazakhstan to France for 2020. Thus, $1^{\text {st }}$ quarter is equal to $€ 34775013 ; 2^{\text {nd }}$ quarter is equal to $€ 61623003 ; 3^{\text {rd }}$ quarter is equal to $€ 47247981$ and $4^{\text {th }}$ quarter is equal to $€ 64616495$. The dynamics of the time series for 2020 will be positive from $1^{\text {st }}$ to $2^{\text {nd }}$ and $3^{\text {rd }}$ to $4^{\text {th }}$ quarters.

\section{Kazakhstan - the Netherlands (table 5, figure 5)}

As a part of the analysis, it is known that the dynamics of growth in oil and gas exports from the Republic of Kazakhstan to the Netherlands had a fluctuating trend. The maximum export volume was in the $4^{\text {th }}$ quarter of 2012, where it was equal to $€ 52360$ 782. The minimum export volume was in the $4^{\text {th }}$ quarter of 1999 , where it was equivalent to $€ 3613666$. As you can see, the long-term trend of product exports is obscured by many fluctuations. Thus, visual analysis of the graph does not allow us to say that the data is trending. Considering this issue, we applied the moving average and centred moving average methods. After using these methods, we calculated that the maximum and minimum centred moving values were equal to $€ 43801802$ in $4^{\text {th }}$ quarter in 2012 and $€ 4628571$ in $3^{\text {rd }}$ quarter, 1999, respectively.

As a result of the analysis of the multiplicative model of time series there was predicted the dynamics of export of oil and gas of Kazakhstan to the Netherlands for 2020. Thus, $1^{\text {st }}$ quarter is equal to $€ 36748945 ; 2^{\text {nd }}$ quarter is equal to $€ 42292080 ; 3^{\text {rd }}$ quarter is equal to $€ 42767699$ and $4^{\text {th }}$ quarter is equal to $€ 47908$ 338. The dynamics of time series will be positive from $1^{\text {st }}$ quarter till $4^{\text {th }}$ quarter of 2020.

\section{Kazakhstan - Poland (table 6, figure 6)}

As a part of the analysis, it is known that the dynamics of growth in oil and gas exports from the Republic of Kazakhstan to Poland had a fluctuating trend. The maximum export volume was in the $3^{\text {rd }}$ quarter of 2019, where it was equal to $€ 74563$ 190. The minimum export volume was in the $1^{\text {st }}$ quarter of 2000, where it was equivalent to $€ 2318207$. As you can see, the long-term trend of product exports is obscured by many fluctuations. Thus, visual analysis of the graph does not allow us to say that the data is trending. Considering this issue, we applied the moving average and centred moving average methods. After using these methods, we calculated that the maximum and minimum centred moving values were equal to $€ 39633463$ in $1^{\text {st }}$ quarter in 2013 and $€$ 3140391 in $3^{\text {rd }}$ quarter, 1999, respectively.

As a result of the analysis of the multiplicative model of time series there was predicted the dynamics of export of oil and gas of Kazakhstan to Poland for 2020. Thus, $1^{\text {st }}$ quarter is equal to $€ 28581488 ; 2^{\text {nd }}$ quarter is equal

Table 5 Historical data of time series from 1999 till 2020 for export of oil and gas to the Netherlands

\begin{tabular}{|c|c|c|c|c|c|c|c|}
\hline$t$ & Year & Quarter & Export value & Moving average (4) & Deseasonalize & Tt & Forecast \\
\hline 81 & \multirow{4}{*}{2019} & 1 & $€ 28524534$ & $€ 36857173$ & $€ 32659433$ & $€ 40542147$ & $€ 35409245$ \\
\hline 82 & & 2 & $€ 42633225$ & $€ 38671540$ & $€ 42802021$ & $€ 40925623$ & $€ 40764227$ \\
\hline 83 & & 3 & $€ 42648921$ & $€ 39415285$ & $€ 42724014$ & $€ 41309099$ & $€ 41236493$ \\
\hline 84 & & 4 & $€ 43854459$ & & $€ 39568764$ & $€ 41692574$ & $€ 46208299$ \\
\hline 86 & \multirow{3}{*}{2020} & 2 & & & & $€ 42459526$ & $€ 42292080$ \\
\hline 87 & & 3 & & & & $€ 42843001$ & $€ 42767700$ \\
\hline 88 & & 4 & & & & $€ 43226477$ & $€ 47908339$ \\
\hline
\end{tabular}

Source: own elaboration based on ec.europa.eu (2020)

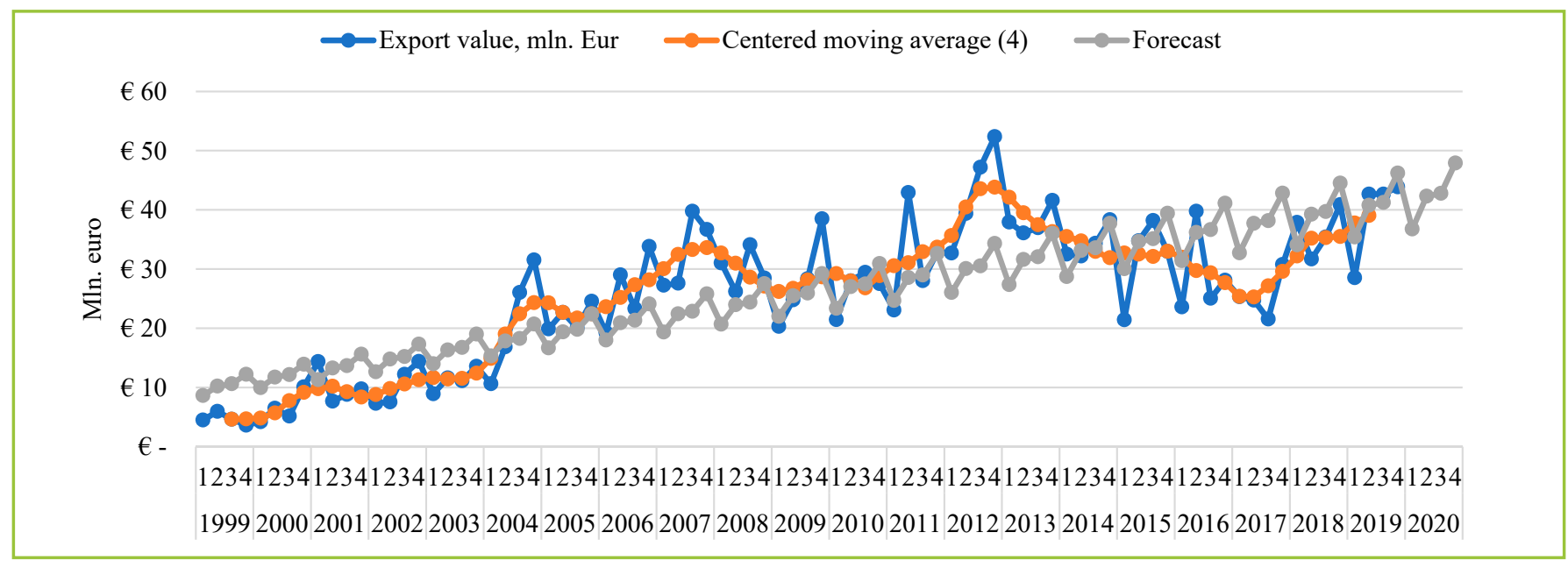

Figure 5 Time Series analysis and forecasts for oil and gas export to the Netherlands Source: own elaboration based on ec.europa.eu (2020) 
Table 6 Historical data of time series from 1999 till 2020 for export of oil and gas to Poland

\begin{tabular}{|c|c|c|c|c|c|c|c|}
\hline$t$ & Year & Quarter & Export value & Moving average & Deseasonalize & Tt & Forecast \\
\hline 81 & \multirow{4}{*}{2019} & 1 & $€ 22339738$ & $€ 32704713$ & $€ 34125911$ & $€ 41746995$ & $€ 27328705$ \\
\hline 82 & & 2 & $€ 43320598$ & $€ 43034482$ & $€ 43415316$ & $€ 42225429$ & $€ 42133307$ \\
\hline 83 & & 3 & $€ 74563190$ & $€ 48023072$ & $€ 66760244$ & $€ 42703864$ & $€ 47695097$ \\
\hline 84 & & 4 & $€ 51868760$ & & $€ 43081299$ & $€ 43182298$ & $€ 51990359$ \\
\hline 85 & \multirow{4}{*}{2020} & 1 & & & & $€ 43660732$ & $€ 28581488$ \\
\hline 86 & & 2 & & & & $€ 44139167$ & $€ 44042870$ \\
\hline 87 & & 3 & & & & $€ 44617601$ & $€ 49832512$ \\
\hline 88 & & 4 & & & & $€ 45096035$ & $€ 54294449$ \\
\hline
\end{tabular}

Source: own elaboration based on ec.europa.eu (2020)

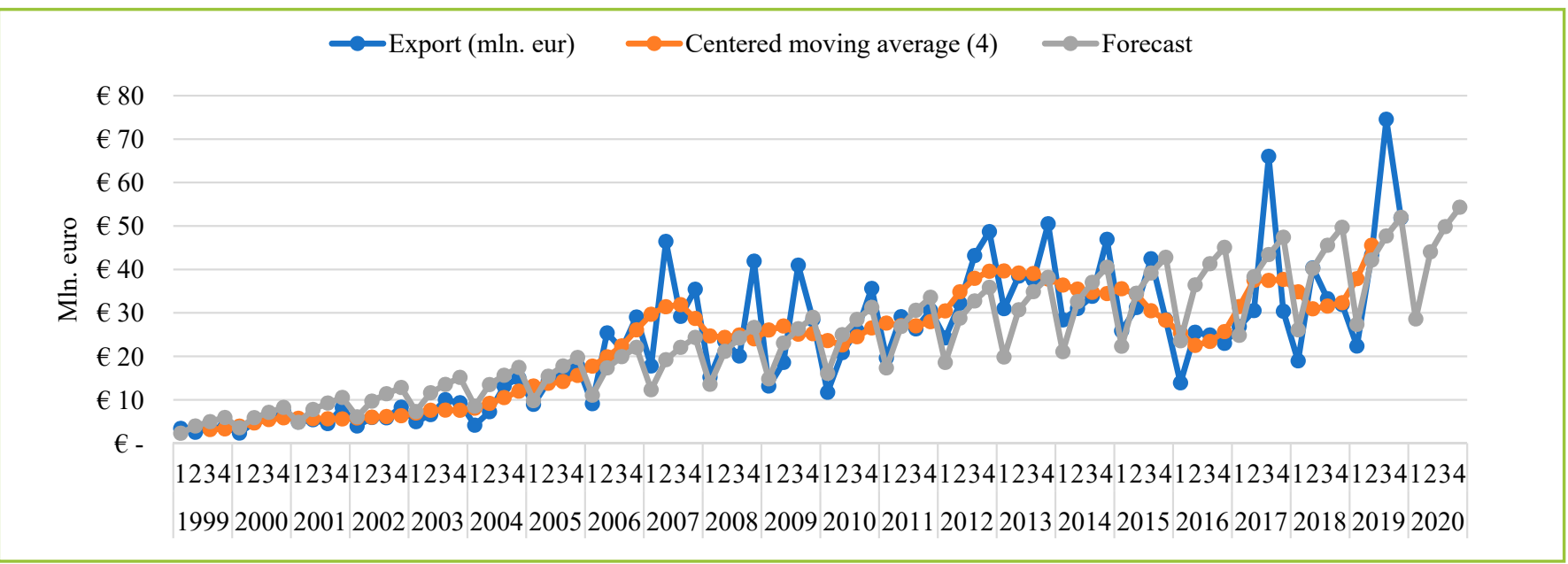

Figure 6 Time Series analysis and forecasts for oil and gas export to Poland Source: own elaboration based on ec.europa.eu (2020)

to $€ 44042869 ; 3^{\text {rd }}$ quarter is equal to $€ 49832511$ and $4^{\text {th }}$ quarter is equal to $€ 54294$ 449. The dynamics of time series will be positive from $1^{\text {st }}$ quarter till $4^{\text {th }}$ quarter of 2020.

\section{Conclusions}

The purpose of the research paper was to analyse the oil and gas trade between Kazakhstan and the European Union using a time series model to examine Kazakhstan's oil and gas trade flow, in order to describe its top 5 trade partners in the EU, also providing objective information on the results and prospects of development of cooperation between Kazakhstan and the European Union in the field of oil and gas trade. In order to analyse Kazakhstan's oil and gas trade with the European Union, we conducted statistical macro and micro analyses, such as time series, namely multiplicative model in order to predict future trends and trading potentials of the two markets and identify Kazakhstan's top 5 partners in the European Union trade in oil, gas and oil products and give a forecast of dynamics of oil and gas export from Kazakhstan to the European Union members. Based on the results, we identified the top 5 partners of Kazakhstan in the European Union. They are Germany, Italy, France, the Netherlands, and Poland.

\section{References}

ANDERSON, J.E. A Theoretical Foundation for the Gravity Equation. In American Economic Review, vol. 69, 1979, no. 1, pp. 106-116.

ANDERSON, J.E. - LARCH, M. - YOTOV, Y.V. 2015. Growth and Trade with Frictions: A Structural Estimation Framework : NBER Working Paper № 21377, 2015.

BAIER, S.L. - BERGSTRAND, J.H. 2009. Bonus Vetus OLS: A Simple Method for Approximating International Trade-cost Effects Using the Gravity Equation. In Journal of International Economics, 2009, no. 77, pp. 77-85.

BABAK, V. The oil and gas sector in Kazakhstan. Tel Aviv : Center for Russian and European Studies, University, $41 \mathrm{p}$.

EgGER, P. - PFAfFermayr, M. The Proper Panel Econometric Specification of the Gravity Equation: A Three-way Model with Bilateral Interaction Effects. In Empirical Economics, 2003, no. 28, pp. 571-580.

EUROSTAT. 2020. Database. [online]. [cit. 2020-03-05]. Retrieved from: https://ec.europa. eu/eurostat/data/database

KETOVA, 0. Production of primary energy in Kazakhstan. The United Nations Economic Commission for Europe (UNECE) report, 2018, no. 2500145107.

LAUMULIN, M. Central Asia and the European Union: Towards the new EU Regional Strategy. In Central Asia's Affairs, 2020, pp. 11-12.

\section{Contact address}

Alisher Yerkinuly Kabylda, Slovak University of Agriculture in Nitra, Faculty of Economics and Management, Department of Economics, Tr. Andreja Hlinku 2, 94976 Nitra, Slovakia, 5 ? +4213764145 85, e-mail: xkabylda@is.uniag.sk 